\title{
Putting Thoughts to Work: Concepts, Systematicity, and Stimulus-Independence*
}

\author{
ELISABETH CAMP \\ University of Pennsylvania
}

\begin{abstract}
I argue that we can reconcile two seemingly incompatible traditions for thinking about concepts. On the one hand, many cognitive scientists assume that the systematic redeployment of representational abilities suffices for having concepts. On the other hand, a long philosophical tradition maintains that language is necessary for genuinely conceptual thought. I argue that on a theoretically useful and empirically plausible concept of 'concept', it is necessary and sufficient for conceptual thought that a thinker be able to entertain many of the potential thoughts produced by recombining her representational abilities apart from a direct confrontation with the states of affairs being represented. Such representational abilities support a cognitive engagement with the world that is flexible, abstract, and active.
\end{abstract}

What does it take to think? Or, if we acknowledge different kinds of thinking, what is necessary for distinctively conceptual thought? A venerable philosophical tradition, tracing from at least Descartes, maintains that conceptual thought requires language. A more recent tradition, based largely in cognitive psychology and ethology, maintains that any animal who represents and responds to different aspects of its environment in a systematic manner thereby deploys concepts. ${ }^{1}$ One might assume that because these two traditions focus on such different phenomena, they must mean utterly disparate things by 'concept' and

Thanks to Jake Beck, Peter Godfrey-Smith, John Hawthorne, Susanna Siegel, and Dmitri Tymoczko for extensive discussion. Thanks also to the MBPA discussion group, and to audiences at talks at the University of Maryland and the Rutgers University Center for Cognitive Science from which this paper is drawn.

1 Cf. e.g. Hernnstein et al 1976, Gallistel 1990, Hauser 2000, Hauser et al 2002, Allen and Hauser 1996 and many of the other essays collected in Bekoff and Jamieson 1996. Developmental psychologists also apply the term 'concept' fairly freely to infant cognition: cf. e.g. Carey 1985, Spelke 1985. 
'thought', and so that there can't be any hope of reconciling them. I don't think this is right. I will argue that the scientific tradition reflects an important insight about the underlying mechanisms that enable a thinker to think, while the philosophical tradition captures an important insight about what thinkers can do with their thoughts. I believe we can bring these insights together in a well-motivated and practically useful account that captures the core set of cognitive tasks that we expect concepts to perform.

Theorists from both traditions typically agree that conceptual thought involves an important sort of systematicity. I'll start by sketching an argument for the view, which I'll call "minimalism," that any representational abilities that can be systematically recombined are eo ipso conceptual. In $\$ 2$, I turn to an argument for the opposite view, which I'll call "intellectualism," that language-or at least a capacity for thinking about one's thoughts, which is assumed to be possible only through language - is necessary for conceptual thought. Although the intellectualist argument is untenable, in $\S 3$ I extract a weaker criterion that I think is plausible: the requirement of stimulus-independence. Thought that results from systematically recombinable, stimulus-independent representational abilities is flexible, abstract, and actively self-generated, and thus quite unlike mere passive reaction to stimuli. In $\$ \S 4$ and 5 , I argue that a significant degree of stimulus-independence is possible in the absence of language, but that it is unlikely to support fully systematic recombinability. However, given that even language doesn't guarantee full recombinability, I conclude in $\$ 6$ that it would be arbitrary to insist that creatures without absolutely general recombinability fail to think conceptually. If we focus on the practical advantages conferred by conceptual thought, we can understand why and how it might emerge in nature.

\section{§1: Minimalism}

Any theory of thought must begin with the basic task of thought: representing the world. Beliefs represent the world as being a certain way, while desires represent a way that the world should be, by the thinker's lights. Further, beliefs and desires don't operate in isolation: they interact with other beliefs and desires to guide action. These basic criteria for thought in turn give us some grip on the basic task of concepts. Where a belief or a desire represents an entire state of affairs, and so is typically specified by a whole sentence, like "This apple is red," a concept represents a particular thing or way for something to be, and so is typically specified by just a word or phrase, like "this apple" or 
"is red." These representations of particular objects and properties combine to form representations of entire states of affairs.

This line of thinking underwrites one of the few widely shared intuitions about concepts: that conceptual thought is essentially structured. Begin with the idea that there are important commonalities among the various thoughts a subject can think. As Gareth Evans $(1982,100)$ puts it:

It seems to me that there must be a sense in which thoughts are structured. The thought that John is happy has something in common with the thought that Harry is happy, and something in common with the thought that John is sad.

So far as Evans's observation here goes, the "commonality" in question might simply be one of referential content. After all, the two thoughts that John is happy and that Harry is happy "have something in common" merely in virtue of both being about someone's being happy. In principle, it's possible that a thinker might be able to think both of those thoughts, but that her ability to think each one was utterly independent of her ability to think the other. In the same way, a photo of John being happy and a photo of Harry being happy have in common that they're photos of happy people; but they need not share any configuration of pixels, nor need there be anything common to the causal processes which produced them that isn't also shared by every other photograph. If the two thoughts likewise shared a structural commonality merely at the level of referential content, they could still perform the basic job of belief - so long as they were formed and extinguished in the appropriate circumstances, and produced appropriate further actions when co-instantiated with other attitudes.

In that case, though, there would also be nothing about those beliefs that could serve the basic job of concepts: of representing particular individuals and ways of being. There would thus be no point in attributing concepts to that thinker; we could simply describe its thinking in terms of whole beliefs about entire states of affairs. For a thinker's representational abilities to be conceptual in a non-trivial sense, the commonality Evans identifies can't just be a descriptive similarity at the level of referential content. Rather, the reason the thinker can think both that John is happy and that Harry is happy must be that she has an underlying ability to think about being happy: to represent that way for things to be. Likewise, the reason a thinker can think both that John is happy and that John is sad must be that she has an underlying ability to think about John. Conceptual thoughts are structured, then,

For simplicity, I largely ignore the difference between singular and predicative concepts, as well as relational and second-order concepts. 
at least in the sense that the ability to think them results from the exercise of distinct, systematically interacting representational abilities. ${ }^{3}$

But now, it seems that insofar as a thinker really does have an ability to represent how it is for something to be happy-to represent that way for things to be-then she should be able to apply that ability, not just in thinking about John and Harry, but in thinking about other things as well. Similarly, if she really has an ability to think about John, then she should be able to think of him not just as being happy or sad, but also as being bald or tall. This gives us Evans's $(1982,104)$ "Generality Constraint:"

If a subject can be credited with the thought that $a$ is $F$ then he must have the conceptual resources for entertaining the thought that $a$ is $G$, of every property of being $G$ of which he has a conception.

That is, because concepts represent particulars and ways of being as such, they should be capable of representing those particulars and ways of being across the board, and not just in specific instantiations in specific states of affairs. There may, as Christopher Peacocke $(1992,43)$ suggests, be strange chemical reactions, psychological traumas, or other

Cf. Fodor 1987, Fodor and Pylyshyn 1988, Davies 1991. Fodor and others take the argument for systematically interacting abilities to establish that there must also be correlatively structured vehicles of thought. Like Evans (1982, 100), I want to remain neutral about the need for symbols in thought: that is, entities with formal, syntactic properties as well as semantic, representational ones (see my 2007 for discussion of the Language of Thought hypothesis and thought with non-linguistic vehicles). Further, where much of the discussion of conceptual thought, especially in relation to perception, focuses on a certain kind of content - conceptual content-I restrict my attention to conceptual abilities. I do this for several reasons. First, Evans himself frames the Generality Constraint, below, in terms of "conceptual resources;" other parties to the debate about what constitutes conceptual thought, such as McDowell (1994), Davidson (1975/1984, 1982, 1999), Peacocke (2001), and Carruthers (2004), also discuss the issue in terms of resources or abilities. Second, I think it is most useful to treat "content" as denoting either a representational state's satisfaction-conditions or the combination of objects and properties it is about, and as excluding the way that the thinker represents them. Distinguishing referential contents from modes of presentation allows us to state clearly both what's common to and what's different about two photos of John kissing Mary taken from different angles, an utterance of "John is kissing Mary," and an utterance by John of "I am kissing her" about Mary. Third, those who endorse a distinction between conceptual and non-conceptual content, as Evans, McDowell, Peacocke, and others do, still posit an intimate connection between conceptual contents and abilities. That is, they acknowledge that two mental states, one with conceptual and the other with nonconceptual content, can be about just the same objects and properties; the kind of content that each mental state has is determined by the abilities that must be exercised in order to grasp that content (cf. e.g. Crane 1992, Heck 2000, Byrne 2004, Speaks, 2005). Because I take the question of conceptual abilities to be more basic, I restrict my attention to it, and leave those who are so inclined to draw implications about types of content. 
external factors that prevent a thinker from entertaining specific thoughts. But as far as the conceptual abilities themselves go, it seems there's something wrong with someone who can make perfect sense of John, Dick, and Harry being happy, but not George.

So, for talk of concepts to do any explanatory work, a thinker's ability to represent entire states of affairs must be produced by systematically recombinable constituent representational abilities. By itself, systematic representational recombinability is merely a necessary condition on conceptual thought. And obviously, it cannot also be a sufficient condition. The different states of an abacus represent different states of affairs; which states they represent is systematically determined by the particular combinations of its beads; and transitions between represented states are caused by systematically recombining beads. But the states of the abacus are not thoughts, and the beads are not concepts. Nor are the various states of the nerves in my stomach, even if the nerves respond systematically to the quantity, fat content, and spiciness of my diet, and even if they control various digestive enzymes on this basis.

For a state or disposition to even be a candidate for being conceptual, it must be cognitive. Just what this requires is a highly contentious question in its own right. Roughly, capitalizing on the views of theorists like Jerry Fodor (1987, 1990), Fred Dretske (1990, 1994, 1999), and Ruth Garrett Millikan (1984, 1986, 1998), I'll assume that cognitive states and abilities have the function of indicating or representing aspects of the world, and are capable of interacting with a range of other such states and abilities to produce action aimed at achieving the creature's goals. ${ }^{4}$ Further, although the basis for a cognitive ability may be sensory or innate, I will assume that the ability must itself be applicable on the basis of, and revisable as a result of, a range of different experiences; this differentiates cognitive states from purely perceptual ones while also allowing for the possibility of innate concepts like object or agent (Spelke 1985). ${ }^{5}$

While Fodor disagrees with Dretske and Millikan about whether we can use biological functions to derive the contents of thought, he agrees that beliefs and desires themselves have the function of indicating. Dretske, but not Fodor or Millikan, requires that the cognitive states be learned.

5 Allen and Hauser (1996) take a closely related pair of requirements to be the core of conceptual (as opposed to merely cognitive) ability:

First, an organism whose internal representations are concept-like should be able to generalize information obtained from a variety of perceptual inputs and use that information in a range of behavioral situations.... Second, organisms that can be said to possess a concept should be able to alter what they take as evidence for an instance of that concept.

Someone might think that this is too restrictive for basic cognition, perhaps because they wanted to treat perceptual states as cognitive. If so, these requirements could be added to basic cognition to produce what minimalism about concepts, or else discarded entirely to produce an even more minimal minimalism. 
I'll call states and abilities that meet these conditions "basic cognition." While there is little agreement about how the contents of these states might be derived naturalistically, I take the conditions themselves to be fairly plausible. Those who prefer an alternative characterization should be able to reformulate the discussion in their own terms without altering the overall dialectic dramatically. ${ }^{6}$

The minimalist about concepts claims that systematically recombinable cognitive abilities are eo ipso conceptual, because that they satisfy all of the basic tasks we've identified for concepts to perform. First, a range of animals manifest complex patterns of behavior which warrant postulating systematically recombinable representational abilities. For the attribution of any representational ability to be genuinely explanatory, that ability must be capable of being exercised on multiple occasions and in multiple contexts: as Bermudez $(2003,97)$ says, it must be "projectable." If a creature invariably responds to a variety of situations with the very same behavior, then we should conclude that it is simply representing or responding to some particular feature, or class of features, that is common to all those situations - we wouldn't yet have uncovered enough behavioral complexity to justify postulating recombinable representational abilities. However, if we find systematic patterns of constancy within significant variation in a creature's responses to different situations, then there is explanatory work for recurrent, interacting representational constituents to do.

To take a simple example, a $\operatorname{dog} D$ might encounter several different $\operatorname{dogs} M, N$, and $O$ upon multiple occasions, and treat each of the dogs differently when it does. For instance, $M$ 's behavior on one occasion might cause $D$ to treat it as a hunting partner on that occasion, while it treats $N$ as a playmate and $O$ as a threat to its dominance. These experiences might then in turn affect how $D$ treats each of the dogs when it encounters them again. On a future occasion, say, $D$ might treat $M$ as a threat to its dominance; but the threat-response behavior it directs toward $M$ might differ from the behavior it directs toward $O$ when it treats $O$ as a threat.

The most efficient explanation of this overall pattern of behavior will appeal to recurrent roles played by interacting representational abilities.

6 Thus, on the one hand, those who hold that something more than basic cognition is required for conceptual thought typically acknowledge the existence of a more basic, non-conceptual form of representation - "proto-thought" - and remain neutral about its minimal requirements. (In $\S 3$, I'll consider an argument that proto-thoughts can't be representational; but there too, the details of what we mean by basic cognition or proto-thought won't matter.) On the other hand, if those who claim that even basic cognition is itself conceptual choose to adopt weaker, more inclusive criteria for basic cognition than I do, then they make their position stronger, and hence easier to falsify, than it is on my construal; while if they adopt more stringent criteria, then any conclusions I derive for basic cognition will also apply to their construal. 
To explain $D$ 's later behavior, it's not enough to attribute to $D$ just an ability to represent $M$, because it treats $M$ differently on different occasions. Nor is it enough to attribute to it just an ability to represent threats, because it treats $M$ differently from $O$ when it treats them both as threats. We could postulate entirely distinct, unstructured representations of $M$-as-hunter, $M$-as-threat, and $O$-as-threat; but then it would remain a mystery why we find the commonalities we do across $D$ 's behavior, whenever it encounters $M$, for instance. A much more parsimonious explanation of the overall pattern of behavioral constancy within difference is that $D$ has distinct abilities to represent $M, N$ and $O$, and to represent hunter, playmate and threat, and that its later behavior toward $M$ is the combined result of its representations of $M$ and threat.

Further, we can imagine events playing out so that $D$ ends up combining each of its abilities to represent $M, N$, and $O$ with each of its abilities to represent hunter, playmate, and threat. Maybe $N$ happens to be a particularly innocuous dog, so that $D$ never actually has an occasion to represent $N$ as a threat. But in principle, it might seem that $D$ is perfectly capable of representing that state of affairs should the occasion arise. And if that's right, then it appears that we have good reason to credit $D$ with constituent representational abilities that are capable of being recombined generally.

The second reason for claiming that systematically recombinable cognitive abilities are eo ipso conceptual is that, in addition to making a common contribution to distinct representational states, such cognitive abilities also underwrite transitions between states in virtue of their common contributions to them. Peter Carruthers $(2004,216)$ appeals to this idea in claiming that even bees have concepts:

For if one and the same item of directional information can be drawn on both to guide a bee in search of nectar and to guide the same bee returning to the hive, then it would seem that the bee must be capable of something resembling the following pair of practical inferences (using BEL to represent belief, DES to represent desire, MOVE to represent action-normally flight, but also walking for short distances - and square brackets to represent contents).

(1) BEL [nectar is 200 meters north of hive]

BEL [here is at hive]

DES [nectar]

MOVE [200 meters north] 
(2) BEL [nectar is 200 meters north of hive]

BEL [here is at nectar]

DES [hive]

MOVE [200 meters south]

These are inferences in which the conclusions depend upon structural relations amongst the premises.

As before, we cannot explain the commonalities we observe in the bee's behavior unless we attribute to it the recurrent abilities to represent hive, nectar, here, and the spatial relation between nectar and hive. But further, it's only because these same representational abilities are exercised in different combinations in each of the beliefs and desires in (1) and (2), and because those beliefs and desires interact in virtue of those recurrent constituents, that the overall sets of attitudes in (1) and (2) produce the actions they do. If one accepts that basic cognitive abilities must be applicable on the basis of a variety of sensory inputs and revisable in the light of experience, as I do, then it's not clear that bees' representational abilities are genuinely cognitive. But Carruthers's argument extends to many other animals, such as rats and ravens, whose representational abilities do meet these basic conditions.

If this is right, though, then basic cognitive abilities perform all the tasks we originally demanded of concepts. They enable a creature to represent particular individuals and aspects of the world; they combine in different ways on different occasions to produce systematically related representations of various entire states of affairs; and they underwrite interactions between those representations in systematic ways that conduce to achieving the creature's goals. Such representational abilities are also abstract and flexible, insofar as they are not tied to any particular perceptual input or behavioral output, but can be applied in multiple combinations and in multiple contexts. Thus, if we want to resist the minimalist view, we either need to identify some additional task for concepts to do, or else show that basic cognitive abilities don't in fact fulfill one of the tasks that we've already identified.

\section{§2: Intellectualism}

I'll return in $\S 5$ to the question of whether creatures with basic cognition can in fact recombine their representational abilities generally, in the way I suggested that the $\operatorname{dog} D$ in our toy example could. For now, let's 
grant that such animals satisfy the Generality Constraint in principle. Even so, the sort of thinking that dogs and rats do is obviously quite different from the sort of thinking we do, where 'we' isn't limited to highly educated adults. Most normal seven-year-olds can engage in something like the following train of thought and action: they can wonder what a peanut butter and mayonnaise sandwich would taste like, make one and take a bite from it, discover that it's nasty and throw it away, and lie to their father when asked about the half-eaten remains. No other animals seem capable of anything like these thoughts, even after extensive training. Why not? It's certainly possible that these differences in cognitive ability result, not from the addition of any single ability, but from a suite of unrelated abilities. It's also possible that only anthropocentric prejudice leads us to assume that if there were some crucial difference between us and other animals, it would reflect something important about thought itself. Nonetheless, a long philosophical tradition insists that there is indeed a crucial difference, and that this difference is, or at least is closely associated with, the ability to speak a language.

I'll call the view that only creatures with language can think "intellectualism." Here is Descartes, perhaps the archetypal intellectualist:

For it is quite remarkable that there are no men so dull-witted or stupid-and this includes even madmen - that they are incapable of arranging various words together and forming an utterance from them in order to make their thoughts understood; whereas there is no other animal, however perfect and well-endowed it may be, that can do the like.... This shows not merely that the beasts have less reason than men, but that they have no reason at all: for ... it would be incredible that a superior specimen of the monkey or parrot species should not be able to speak as well as the stupidest child-or at least as well as a child with a defective brain - if their souls were not completely different in nature from ours $(1637 / 1985,140)$.

In this passage, Descartes merely points to the enormous gap in linguistic communicative ability between people and brutes, and concludes that only humans are really capable of reason.

In a more recent defense of intellectualism, Donald Davidson (1975/ $1984,170)$ connects thought to language by way of the concept of error:

Can a creature have a belief if it does not have the concept of belief? It seems to me that it cannot, and for this reason. Someone cannot have a belief unless he understands the possibility of being mistaken, and this requires grasping the contrast between truth and error true belief and false belief. But this contrast ... can emerge only in the context of interpretation, which alone forces us to the idea of an objective, public truth. 
Davidson's argument here can be put in the form of a valid inference from three premises:

(1) in order to have a belief, one must understand the possibility of being mistaken;

(2) in order to understand the possibility of being mistaken, one must have a concept of belief;

(3) in order to acquire the concept of belief, one must interpret another's linguistic utterances.

Therefore, belief requires language.

Of these, the second premise seems fairly hard to deny: even if not all mistakes are false beliefs, the two are intimately intertwined. The third premise, though, is quite implausible; even Davidson acknowledges that he doesn't know how to justify it. He sometimes claims that the idea of belief "is not intelligible except as an adjustment to the public norm provided by language" $(1975,170)$. But as I argued in $\S 1$, we can get a grip on the concept of belief without appealing to language: a belief is a mental state with the function of representing the world as being a certain way, that is satisfied just in case the world is that way, and that is available for the believer's use in combination with other representations in satisfying its goals. More often, Davidson says that he can't imagine how one could acquire the concept of belief except by way of linguistic interpretation (e.g. 1982, 327). But this is also quite doubtful. Prima facie, it seems that one might acquire the concepts of belief and error by interpreting the unexpected non-linguistic behavior of others, and that one might usefully apply those concepts to deceive others and detect their attempts at deception. And in fact, empirical evidence suggests that early humans developed a fairly robust capacity for theory of mind before they began to communicate linguistically. ${ }^{7}$

In any case, Davidson is only committed to the claim that language and linguistic interpretation are necessary means for acquiring the concept of belief; he doesn't claim that they are essential to the

Thus, Mithen (Mithen, 1996) argues on the basis of archeological evidence that humans began to live and hunt in fairly large, hierarchically structured groups, and thus needed sophisticated social intelligence, well before they developed language (see also Gibson and Ingold 1993). Similarly, Tomasello (2000) argues that the crucial adaptation that underwrote the development of language was the emergence of a capacity to coordinate social attention. Davidson comes close to accepting the emergence of social intelligence before language in his (1999). 
concept itself. Thus, at least for our purposes, the real weight of the argument rests on his first premise. The requirement that one understand the possibility of being mistaken might be construed in several ways. It might require either that one believe that one's own beliefs could be in error, or else that someone else's could; likewise, it might require that one believe, of every belief in a given set, that it might be in error, or else just that one believe that there might be some false belief or other in the set. All of these variations share two basic assumptions, though: first, in order to think conceptual thoughts, one must be able to think higher-order (specifically, modal) thoughts about thoughts and their truth-values; and second, one must realize that beliefs "aim at" truth.

In contrast to the third premise, Davidson never even attempts to justify these assumptions explicitly; he seems to find them too obvious to merit discussion. I suspect, however, that he believes that if a creature lacked these meta-representational abilities, then it wouldn't have the sort of control over forming and revising its cognitive states that should be required for genuine belief. It would be at the mercy of its environment - a mere passive reactor. And in that case, we wouldn't yet have real representation at all, but just a sea of shifting responses to stimuli. John McDowell (1994, 11-12) explicitly employs this notion of active control to motivate the claim that genuinely conceptual abilities require the ability to think about one's thoughts:

[T] he capacities that are in play in experience ... would not be recognized as conceptual capacities at all unless they could also be exercised in active thinking.... Minimally, it must be possible to decide whether or not to judge that things are as one's experience represents them to be.... Active empirical thinking takes place under a standing obligation to reflect about the credentials of the putatively rational linkages that govern it. ${ }^{8}$

$8 \quad$ Cf. also: "It is ... the power of conceptual thinking that brings both the world and the self into view. Creatures without conceptual capacities lack self-consciousness and - this is part of the same package - experience of objective reality" (114); "In the context of insulation from spontaneity, the talk of concepts is mere word-play" (52). At other points, McDowell seems to suggest that active reflection on one's own thoughts is necessary only for a particularly stringent type of conceptuality: "It is essential to conceptual capacities, in the demanding sense, that they can be exploited in active thinking, thinking that is open to reflection about its own rational credentials" (47); "If someone wants to work out a conception of orientation towards the world that is detached from spontaneity in the Kantian sense, with a view to making the language of world-directedness available for talking about the mentality of brutes, that is, so far, perfectly all right by my lights" (183). Although I think the hard-line view fits better with McDowell's overall position, I won't takes sides on the exegetical issue here; if the permissive interpretation is correct, my project can be seen as an attempt to work out a less demanding sense of conceptuality. 
Like Davidson, then, McDowell wants to forge a constitutive link between conceptuality and thought about thought, by invoking the need for a capacity to reflect on the possibility of error. And like Davidson, McDowell assumes that this is only possible in the context of language (cf. also Bermudez 2003, ch. 8).

Clearly, we should agree that a measure of active rationality is necessary for thinking of any sort: a creature who systematically refused to revise its beliefs in the light of overwhelming countervailing evidence would arguably be too irrational to count as thinking at all. However, creatures with mere basic cognition are generally capable of revising their beliefs when their expectations aren't met; that's an essential part of their capacity to learn. We've also required that creatures with basic cognition be able to revise their grounds for instantiating a concept. This falls well short of explicitly appreciating the possibility of error, to be sure. But I don't see any justification for imposing such a strong requirement. There is a vast difference between being able to use concepts to think about the world and being able to think about one's thoughts. Intuitively, three-year-old children appear to possess many concepts, which they apply repeatedly and confidently in various combinations, in order to think and say things about the world, such as "Mommy drinking juice. Bobby wants juice. Mommy give Bobby juice." But they have not yet developed an understanding of false belief, let alone an ability to reflect upon the epistemic credentials of their own beliefs (Wimmer and Perner 1983). Likewise, as Huw Price (1990, 231) notes, early humans were presumably reasoning and talking about the world long before they began to think about their reasons and talk:

It is tempting to think that agronomy is an older profession than epistemology - that we could think, talk and argue about grass (and many other important things) at least an evolutionary step or two before we hit on the concepts of warrant, reason, justification, and the like.

Arguments to the effect that children and early humans are not really deploying concepts to represent the world because they aren't capable of meta-representation will be persuasive only if those arguments rely on premises that are at least as intuitively compelling as the claim that such people are conceptual thinkers. I don't know of any argument that does this.

Mort importantly, by itself the appeal to an explicit appreciation of error doesn't take us much further toward explaining the explosive increase in our own cognitive abilities over basic cognition. It seems plausible that a creature who explicitly reflects upon the epistemic credentials of its thoughts will be more efficient at noticing its errors, and 
that it will therefore learn more efficiently; perhaps it will also be more proactive about seeking evidence to test its beliefs (cf. McGeer and Pettit 2002). But a thinker can only apply epistemic reflection to those first-order thoughts that it already thinks. And by itself, appreciating the possibility of error does little to increase the range of such thoughts, or the range of uses to which the thinker can put them. Nor would bestowing the ability to speak on a creature with basic cognition by itself give it dramatically more to say: it could only express thoughts that it had already been prompted to think, and it would only hear utterances that were produced by other, similarly limited creatures. The really significant difference between creatures with mere basic cognition and us lies in the exponentially greater range of applications we find for our beliefs, rather than in the carefulness with which we form and revise them or in the mere fact that we exchange them with others.

\section{§3: Stimulus-Independence}

Although I think we should reject Davidson's and McDowell's requirement for an explicit appreciation of error, I believe an important insight is lurking in the vicinity. Specifically, many theorists have felt that active, genuinely rational thinking, as opposed to mere passive reaction, requires some sort of "distance" or "separation" between the thinker and what it thinks about. As Adrian Cussins (1992, 659-60) puts it,
An objective world is given to a subject if the content presents something as being independent of the subject's particular abilities and particular location in space and time. But [if] all the "subject" (experiencing organism) has is an experiential awareness of how to move etc. in response to local changes in its environment ... it would be a conception of something as not independent of contin- gent characteristics of the subject itself. The necessary separation between subject and object would not have been achieved.... [W] hat we are after is a metaphysical distance between subject and object, a distance which makes intelligible the subject's being wrong (and therefore also being right) about the object; which provides for the possibility of truth.

Bermudez and Michael Dummett offer closely related intuitions about the need for "distance" or "separation:"

A ... key element of propositional thinking is that propositions should be independent of the particular context of thinking. That is to say, it should be possible to grasp a proposition both without knowing its truth value and without any contact with the state of affairs that proposition is about (Bermudez 2003, 39). 
Proto-thought is distinguished from full-fledged thought ... by its incapacity for detachment from present circumstances... An animal may solve quite complex problems by a process of thinking about the solution ... but its thought, or more exactly, proto-thought, cannot float free but can occur only as integrated with current activity (Dummett 1994, 123). ${ }^{9}$

Finally, McDowell also explicitly invokes a requirement of separation. In arguing that demonstrative concepts can capture fine-grained experiential content, he claims that the ability to identify a particular color is genuinely conceptual because - but only because - "thoughts that exploit it have the necessary distance from what would determine them to be true;" this distance, he insists, "is necessary for it to be recognizable as a thought at all" $(1994,57) .^{10}$

Although these passages differ in significant ways, a common idea runs through them: genuine thought involves a clear distinction between representation and represented, so that the former can occur even in the latter's absence. We might put the point like this. Because thoughts are at least partly constituted by their contents, understanding a thought requires grasping the conditions required for its satisfaction. But if a thinker really does grasp those conditions of satisfaction, as opposed to simply being confronted by the conditions themselves, then its grasp of those conditions should be relatively independent of its current circumstances. Otherwise, the world, and not the thinker, is shouldering the bulk of the representational burden. And if this is so, then that "thinker" really is just a passive reactor.

If we grant that active thought involves some sort of distance from what is represented, then the requirement of epistemic reflectiveness

9 Although he does not employ the metaphor of distance, Peacocke (2001, 260-264) also endorses the view that thought about an objective world requires a conception of the self as distinct from the world, along with a sensitivity to an open-ended range of grounds for establishing and supporting a belief.

McDowell's invocation of distance here may seem to be in tension with his repeated insistence on direct "openness" to the world, as in the following passage:

[T] here is no ontological gap between the sort of thing one can mean, or generally the sort of thing one can think, and the sort of thing that can be the case. When one thinks truly, what one thinks is what is the case ... there is no gap between thought, as such, and the world. Of course thought can be distanced from the world by being false, but there is no distance from the world implicit in the very idea of thought $(1994,27)$.

The tension disappears if we distinguish the act of thinking from the content thought about. The act of thinking requires distance in the sense that the very same conceptual capacities must be capable of being exercised in different circumstances, apart from confrontation with the property being represented; but what is thereby thought about is an aspect of the world itself (or at least, an aspect of how it could be). 
makes considerably more sense. Understanding the possibility that a belief might be false requires understanding that the world might not be that way; and this in turn requires a relatively independent grip on the 'way' the belief represents the world as being. The connection with language, which was previously justified only instrumentally, can now be motivated directly as well. Thus, Noam Chomsky $(1966 / 2002$, 57) advocates the explicitly Cartesian view that only human language, "being free from control by identifiable external stimuli or internal physiological states, can serve as a general instrument of thought and self-expression." Because words enable us to represent objects and properties that are absent from us, they free us from the control of our immediate internal and external circumstances.

The intellectualist claims that by contrast, because creatures with mere basic cognition lack such mechanisms for transcending their circumstances, they cannot achieve the necessary separation. If their internal states are always directly connected to their immediate surroundings, then we don't have any reason to think that those states are really about external circumstances in the world, as opposed to just being regularly correlated with them. And if that's right, then language and/or the explicit appreciation of error turn out to be necessary for accomplishing the most basic task of concepts: representation.

I find the idea that active conceptual thought involves some sort of "separation" compelling; but I don't think the intellectualist can use it to undermine the claim that basic cognitive capacities are representational. To see why not, we need to distinguish two senses in which a creature's representational abilities can be under or free from stimulus control. On the one hand, it is now extremely wellestablished that creatures with no more than basic cognition are not confined to representing only states of affairs that they take themselves to be directly confronting. As Carruthers' discussion of the honeybees reminds us, such creatures can represent states of affairs that they have never actually encountered, and that are distant from them in a quite literal sense of the term. Bees are unusual in having a compositional communicative system: the "waggle dance." But a wide range of animals can represent properties at distant locations, and navigate to those locations by novel routes to satisfy their desires (cf. e.g. Gallistel 1989, 1990). Rats can even navigate to remembered locations without relying on any local landmarks, for instance by swimming to a submerged platform in an opaque pool of water (Morris 1981). Thus, we do have good reason to describe creatures with just basic cognition as capable of transcending their current 
circumstances to represent absent situations, and not merely as responding differentially to immediate stimuli. ${ }^{11}$

At the same time, though, there is another important sense in which creatures with just basic cognition are indeed passive reactors, at the mercy of their environments. It's not what they are capable of representing at all, but rather which thoughts they can think at any given moment, that is controlled by the stimuli they encounter. The only thoughts that such creatures can think are either about states of affairs that are more or less directly indicated by the external stimuli presently impinging on them, or else are about states of affairs that immediately satisfy a present internal stimulus, like hunger or thirst. The relation between any given triggering stimulus and the represented states of affairs can be quite complex — as when a bee's observing a waggle dance causes it to represent a distant nectar source. And a variety of stimuli may cause the creature to represent a given object or property, as when a rat represents food as a result of the smell of food, a red flashing light, or the sound of a bell. But even so, any given stimulus still only triggers a fixed representational ability. This smell, say, indicates (what the creature takes to be) a conspecific; that sound represents prey; this feeling of thirst triggers the representation of one or more water sources. Even when a given stimulus triggers multiple representations of distant states of affairs, as an internal stimulus like thirst might do, the relationship between that triggering stimulus and the represented states is still quite fixed: it is always only water that is represented, say. In this sense, then, creatures with basic cognition are still cognitively limited to representing situations that are directly triggered by current stimuli. So, while they do have minds, they are extremely narrow-minded.

This restriction on which thoughts creatures with mere basic cognition can think in a given situation in turn has implications for the way in which they satisfy the Generality Constraint. They may well satisfy the Constraint in principle, in the sense that if the relevant stimulus were to occur, then this would cause them to combine their representational abilities in the relevant manner. As I said in $\$ 1$, even if the $\operatorname{dog} N$ never actually behaves in a threatening manner toward $D$, it seems that if $N$ were to behave that way, then $D$ would represent $N$ as a threat. Call this a causal counterfactual way of satisfying the Generality Constraint. I'll return in $\S 5$ to whether creatures with basic cognition do actually meet this condition. For now, the mere possibility of causal explain the establishment of associations; mere temporal proximity of stimuli is neither necessary nor sufficient. Rather, association-formation often depends upon statistical temporal correlations among stimuli, which in turn requires a creature to have cognitive access to multiple pairs of stimuli simultaneously. 
counterfactual generality suffices to establish the theoretical distinction between systematicity and stimulus-independence: a creature like $D$ would have systematically recombinable representational abilities in this counterfactual sense while lacking much freedom from stimulus control. Conversely, we can imagine a creature whose thoughts were produced by totally separate, unstructured abilities rather than recurrent, systematically interacting constituent ones, but who could always entertain all of its potential thoughts, whatever its current circumstances.

So in principle, the criteria of systematicity and stimulus-independence are distinct. In practice, though, they are much more intimately connected. A creature with just basic cognition can't really recombine its representational abilities itself; it is dependent upon the stimuli it encounters to prompt it to deploy its abilities. Unless the world presents it with the appropriate stimuli, there is no way it can entertain most of its potential thoughts. Thus, there remains a significant sense in which a creature with mere basic cognition lacks the cognitive resources necessary to recombine its constituent representational abilities generally: it must wait passively for the right catalysts to come along. To achieve an active, self-generated cognitive flexibility, such creatures need more freedom from stimulus control.

Further, unlike the capacity for epistemic reflection, endowing a creature with greater stimulus-independence clearly would make a significant practical difference for it. It would provide cognitive access to a wider range of the world at any given moment, and this in turn would give the creature a richer repertoire of cognitive resources to exploit at a given moment in achieving its goals. By contrast, a creature who could reflect on the epistemic credentials of its beliefs, but whose basic beliefs were still highly stimulus-dependent, or a creature whose capacity for epistemic reflection was itself stimulus-dependent (for instance, who could only reflect upon its epistemic credentials after hearing the ring of a "philosophy bell"), would not be cognitively much better off than a creature who lacked such reflective capacities altogether. The really significant cognitive difference, then, is not the capacity for epistemic reflection or language per se, but rather the capacity for active, self-generated cognition that McDowell and Davidson assume it brings in tow. Thus, I conclude that stimulus-independence — but not language or epistemic reflection-is indeed closely tied to the basic tasks of concepts, either as an independent condition in its own right, or as a practical condition on satisfying the Generality Constraint in a robust way.

\section{§4: Instrumental Reasoning}

I'll return in $\S \S 5$ and 6 to the interactions between systematicity and stimulus-independence and their implications for conceptual thought. 
In this section, I consider how stimulus-independence might be realized in the absence of both language and meta-representation. If the only practical way to achieve a significant degree of stimulusindependence were by way of language or epistemic reflection, then we wouldn't yet have articulated a substantive alternative to intellectualism.

The most minimal and plausible way I can imagine for a creature to achieve greater stimulus-independence is though instrumental reasoning. ${ }^{12}$ When a creature reasons instrumentally, it recognizes a way to achieve a goal that it cannot achieve directly, by bringing about a subsidiary state of affairs. In order to do this, it must represent that subsidiary state while realizing both that this state does not actually obtain and that its obtaining would help to achieve the primary goal. To count as a case of genuine reasoning, the creature's recognition of the connection between the two states must be established through spontaneous "insight": that is, it must be neither directly "afforded" by its environment nor established through trial-and-error or operant conditioning. If a creature does meet all of these requirements, then its representation of the intermediate state of affairs is genuinely instrumental. ${ }^{13}$

In effect, a capacity for instrumental reasoning endows a creature with a new attitude to take toward the contents it represents: that of supposing them to obtain. Creatures with just basic cognition can only represent states that they believe or desire. And by their very nature, these attitudes are highly restricted in their possible objects. However cognitively and conceptually sophisticated I might be, I cannot believe or desire - or indeed, perceive, hope for, fear, or regret - just any old content; substantive further conditions on my internal and external circumstances must also obtain. In this sense, the very attitudes of belief and desire are inherently somewhat stimulus-dependent. By contrast, the attitude of supposing involves considerably fewer internal and external constraints. This greater flexibility in its possible objects in turn makes supposing a suitable

\footnotetext{
12 While instrumental reasoning suffices for increased stimulus-independence, it might not be necessary: an embodied but omnipotent thinker might not engage in practical action but might still represent distant states of affairs.

Bermudez (2003, ch. 7) also appeals to instrumental beliefs, and specifically to tool use, in order to distinguish an important sort of rationality that is possible without language or epistemic reflection - although he scrupulously avoids couching it in terms of conceptual thought. However, he is considerably less concerned than I am to distinguish conditioned from spontaneous instrumental connections, and he does not distinguish the two sorts of stimulus-independence I identified in $\S 3$.
} 
attitude for supporting a more active, self-generated form of cognition. ${ }^{14}$

There is fairly robust empirical evidence that some non-linguistic animals possess some significant capacity for instrumental reasoning. The two most obvious applications involve tool use and social interaction. Tool use requires manipulating one object to achieve a goal with respect to some other one; a wide variety of species, including primates, elephants, polar bears, sea otters, and corvids (crows and ravens), can do this with at least some objects. For instance, wild New Caledonian crows create several different types of implements, which they carry around to retrieve insects from crevices and other inaccessible locations. Different communities of crows learn to form different tools, depending on the available materials and food sources (Hunt and Gray 2004); and crows in novel environments make tools from whatever materials they find, including their own feathers and cardboard. Further, in experimental settings, New Caledonian crows can solve novel food-retrieval problems by selecting novel, appropriate tools; indeed, one crow spontaneously (and then repeatedly thereafter) created a hook from wire - an entirely unfamiliar material, with unfamiliar physical properties like ductility - in order to retrieve food from a basket inside a clear cylinder (Weir et al 2002). ${ }^{15}$

The most famous cases of non-human tool use are probably those reported by Wolfgang Köhler (1925), who observed chimpanzees employing sticks, boxes, and other chimps as props to obtain bananas hanging out of reach; similar observations have been reported more recently with orangutans (Lethmate 1980). It has also been established that chimpanzees, bonobos, and orangutans can discern, from observation alone, the need to untie a stick from a bundle or otherwise modify

14 It is thus notable that Evans formulates the Generality Constraint in terms of the capacity to entertain the full range of one's potential thoughts; a belief-based construal of the Constraint would be much less plausible. Cognitive scientists and developmental psychologists sometimes distinguish three levels of representational ability (Perner 1991, Suddendorf and Whiten 2001). The first, primary representation, is restricted to modeling how the world actually is (or for desires, how it should be). The third, meta-representation, enables a thinker to represent other representations as representations; this is required for epistemic reflection and intentional deception. Between these falls secondary (not second-order) representation: the ability to entertain multiple models while recognizing that they don't all capture how things are. In addition to underwriting instrumental reasoning, a capacity for secondary representation also enables one to engage in pretense.

15 The crow's action was so spontaneous that it disrupted the planned experiment, which was simply to investigate whether the crows could choose task-appropriate tools for a novel set-up. After the male crow flew off with the hooked wire (without having solved the task), the female tried to recover the basket with the straight wire, and then bent it into a hook. A video can be viewed at www.sciencemag. org/cgi/content/full/297/5583/981/DC1. 
a given prop in order to retrieve food from a tube (Visalberghi et al 1995). Dummett (1994, 123) objects that Köhler's observations don't really demonstrate a capacity for instrumental reasoning, because in his experiments both the instrument and the goal were always simultaneously perceptible. However, chimpanzees can also solve complex puzzles, such as mazes, where the appropriate action at any one point depends on recognizing the configurations that would result from a series of contingent future actions (Suddendorf and Whiten 2001). It is also now well established that wild chimpanzees select and produce tools in situations where the goal is not perceptible (Boesch and Boesch 1984, 1990). For instance, chimpanzees in one region of West Africa transport large stones to Panda trees to use as hammers for cracking nuts. And in one region of Central Africa, chimpanzees employ a pair of distinct tools to fish termites from mounds: they first puncture tunnels in the mounds, using stout sticks from a specific kind of tree, and then use 'brushes', which they form by stripping and chewing the ends from a specific species of plant, to fish the termites out. The chimpanzees bring the puncturing sticks to the mound and cache them there for re-use, but because the brushes decay rapidly, they typically arrive at the mound with new brushes formed at the site of the raw plant materials (Sanz et al 2004). ${ }^{16}$ While it is true that these behaviors are habitual rather than spontaneous, they are also culture-specific and naturally arising. Thus, in conjunction with the spontaneous cases cited above, they suggest that unenculturated chimpanzees do have some inherent capacity for non-perceptually-grounded tool use.

Social contexts constitute a second important class of opportunities for spontaneous instrumental action, especially tactical deception. ${ }^{17}$ Among many other observations, one recent experiment provides especially compelling evidence for insightful, non-perceptual instrumental reasoning in chimpanzees (Melis et al 2006). Chimpanzees were first

Videos of the fishing chimpanzees can be viewed at www.journals.uchicago. edu/AN/journal/issues/v164n5/40471/40471.html.

For tactical deception in chimpanzees, see e.g. Whiten and Byrne 1988, Byrne and Whiten 1990, de Waal 1996, Call 2001, Tomasello et al 2003. For tactical deception in ravens, see Bugnyar and Heinrich 2005, 2006. An experiment by Stammbach (1988) suggests that long-tailed macaques can understand how to use others as means to an end, although perhaps only as a result of trial and error. The most subordinate member of a group of macaques was trained to perform a sequence of lever-pressings in order to receive popcorn treats. At first, the dominant members chased the trained subordinate away from the lever, resulting in no popcorn for anyone. Next, they waited until the subordinate had gotten the popcorn before taking it away; this caused him to stop pressing the levers. Finally, they began to wait for him to procure the reward and eat some of it before taking the rest. They also began to groom him even when the machine was not in operation, although there was no general change in the group's dominance structure. 
introduced to a wooden key which they could use to unlock a sliding door to a room where another chimpanzee was held. Next, they were introduced to a feeding platform, which was located out of direct reach but accessible by means of a rope threaded through two metal loops in the platform. The chimpanzees very quickly discerned (often through observation alone) that pulling one end of the rope unthreaded it, leaving the food inaccessible, while pulling both ends brought the platform within reach. When the platform's loops were positioned close enough together for one chimpanzee to reach both rope ends at once, the subject pulled in the platform by himself. When the loops were too far apart, however, most of the chimpanzees - and a majority on the first trialunlocked the door and released the other chimpanzee, who then often collaborated to pull in the platform. When, in a second session, the subjects were introduced to two new collaborators, only one of whom was reliably cooperative, they reliably discerned who was cooperative and chose to unlock his door. Thus, most of the chimpanzees quickly figured out when they needed (and could use) help, how to get it, and who could best provide it. The investigators were most interested in the implications of this third fact for the question of whether chimpanzees possess a theory of mind. For our purposes, though, the second, less controversial feature is more important: that "chimpanzees can quickly adapt a recently learned skill (removing the key) for a novel purpose (initiating a collaborative activity)," in a situation where the connection between implementing the skill and achieving the goal is indirect and not visually perceptible (Melis et al 2006, 1300). The finding is especially surprising given that chimpanzees generally perform better in competitive than cooperative contexts (e.g. Tomasello et al 2003).

One can certainly quibble about whether any of these observations, taken in isolation, conclusively demonstrates a capacity for spontaneous, non-perceptually-afforded instrumental reasoning. Given the range of behaviors that have been observed and the sorts of experiments currently being conducted, I believe this gap will be closed in the relatively near future. ${ }^{18}$ Even without a knock-down demonstration, though, it should be uncontroversial that the sorts of behaviors that have already been observed require a degree of stimulus-independence that goes significantly beyond what can be achieved with basic cognition alone. Creatures with just basic cognition can only undertake actions aimed directly at satisfying their current goals. Their direct action toward that goal may be fairly complex, as when an ant travels a great distance

18 And again, archeological evidence suggests that early humans began to create complex tools, and to live and hunt in large, structured social groups, before they developed language. 
across many obstacles to reach its nest, or when a cat tracks, waits, advances, retreats, and finally pounces on its prey. But these are still recognizably parts of a single action. The twists and turns in the ant's path, for instance, can be explained in terms of the unified goal of getting there from here; when the ant is forced to deviate from its path, it chooses the most minimal alteration available (choosing randomly if confronted with an unfamiliar obstacle perpendicular to its desired path), and then recalibrates its new path using dead reckoning with respect to the sun's position. ${ }^{19}$ Thus, each step the ant takes makes a direct contribution toward its goal, or at most alters the circumstances in a random way to enable it to continue pursuing that goal in the same manner. By contrast, chimpanzees, other apes, and some birds are capable of pursuing a single goal in a variety of ways, by spontaneously engaging in a series of actions, some of which temporarily take them further away from that goal.

\section{§5: The Generality of Conceptual Thought}

Whatever the particular details of various animals' problem-solving abilities, it should be clear as a theoretical matter that a creature with some capacity for insightful instrumental reasoning cannot be utterly narrow-minded: it must be able, from within its current situation, to represent both its goal state and an otherwise disconnected mediating state. By contrast, creatures with basic cognition can only represent states of affairs that they directly desire or that are directly connected to some triggering stimulus. Thus, a capacity for instrumental reasoning entails an increase in stimulus-independence-and with it, a more actively self-generated form of general recombinability. We now need to ask whether a capacity for instrumental reasoning could provide enough stimulus-independence to underwrite fully systematic recombinability.

I think the answer is almost certainly not: it is highly unlikely that a practical ability to reason instrumentally could provide a creature with the ability to entertain all the possible combinations of its representational abilities, whatever its current circumstances. To see this, consider a chimpanzee who can identify some individuals (e.g. that ${ }_{1}$, that ${ }_{2}$, that th $_{3}$ that $_{4}$ ), some properties (e.g. chimpanzee, leopard, dominant, subordinate, threat, mate, offspring, banana, water), and some locations (e.g. there ${ }_{1}$, there $_{2}$, there ${ }_{3}$, here). Let us assume that these representational abilities

19 Müller and Wehner 1988, Schmidt et al 1992, Gallistel 1998. Ants also use landmarks for navigation; when confronted with (what it takes to be) a familiar obstacle, the ant follows the learned route from the end of that obstacle to its nest (Bisch-Knaden and Wehner 2001). 
have the potential, in principle, to be combined into a range of potential thoughts, such as 'that ${ }_{1}$ is offspring', 'that ${ }_{1}$ is subordinate', 'that ${ }_{2}$ is mate', 'that ${ }_{3}$ is banana', 'that $_{2}$ is there, ${ }_{2}$, and 'water is there,'. And let us grant for the sake of argument that the chimpanzee has an extremely robust capacity for instrumental reasoning, so that it can entertain a significant number of these potential thoughts in the absence of any direct triggering stimulus. Even so, it seems clear that many of those potential thoughts will never occur to the chimpanzee, because they are utterly useless for solving any problems that it actually confronts.

It is fairly obvious that necessarily false thoughts, like 'that ${ }_{3}$ is dominant' where that $_{3}$ refers to a banana, lack any practical use. If these were the only useless thoughts, we might explain away the chimpanzee's failure to think them by stipulating that there is simply no thought there to be comprehended: we could restrict the domain of significant application for its concept dominant to chimpanzees and insist that applications outside that domain are either syntactically ill-formed or semantically senseless. ${ }^{20}$ I'll return to the issue of categorially absurd thoughts in $\$ 6$; for now, notice that not all useless thoughts are categorially false. There are also always-true thoughts, like 'banana is food'. More importantly, there are non-absurd, metaphysically contingent thoughts that happen in fact always to be false, such as 'that ${ }_{1}$ is dominant' where that ${ }_{1}$ denotes a highly subordinate chimpanzee, or 'water is there ${ }_{2}$ ' where there $_{2}$ denotes a place where there's never been any water: say, on a slope at the top of a hill. Whether true or false, it would always be a waste of cognitive resources to entertain thoughts like these in a natural environment.

Carruthers $(2004,19)$ acknowledges a parallel point about honeybees: there are many potential thoughts that they too will never form, such as the thought that two potential nest sites are that far apart. However, he argues that this is no obstacle to the bees' achieving full recombinability, and so poses no threat to the claim that their representational abilities satisfy the Generality Constraint, because the bees lack any reason to think these thoughts:

From the fact that bees never form beliefs of a certain kind, it doesn't follow that they can't.... [I]t might just be that bees are only ever interested in the relationships amongst potential new nest sites and the existing colony, and not between the nest sites themselves. But the same sort of thing is equally true of human beings ... there are some things implicit in our beliefs about the world, but never explicitly entertained, either, because they are of no interest. Our beliefs, for example, collectively entail that mountains are less easy to eat than

20 Evans $(1982,101)$, Strawson $(1963,95)$, and Peacocke $(1992,42)$ all endorse categorial restrictions on recombinability of this sort; I argue against categorial restrictions in my 2004. 
rocks.... But until finding oneself in need of a philosophical example, this isn't something one would ever have bothered to think. Likewise with the bees. The difference is just that bees don't do philosophy. ${ }^{21}$

I'll return to the point that one needs a reason to think a thought in a moment. First, we need to ask whether bees and chimpanzees can in fact comprehend thoughts that they lack any reason to think.

By itself, this question is fairly abstract; however, we can exploit the fact that bees in particular have a language-like communication system to make it more concrete. In a famous set of experiments (Gould and Gould 1988, 220; replicated by Tautz et al 2004), honeybees were led to depict a state of affairs that they would normally have no reason to represent. The researchers placed a nectar source on the shore of a lake, and gradually moved it out until it was in the middle of the lake. Bees who visited the source duly returned to the nest and performed a waggle dance indicating the distance and direction of the nectar. Upon being confronted with this dance, though, the bees in the nest did not fly off in search of the nectar, as they would normally do. Instead, they ignored it.

In itself, this is remarkable. Being confronted with a dance depicting a location for food, along with tangible evidence (packed into the scout's collecting pouches) that the food is of high quality, surely raises some interest in the depicted state of affairs. (According to Tautz et al (2004, 918), the dance was performed "with high vigor.") If the bees were reacting only to the information encoded in the dance, then they should have flown off: they wouldn't have any reason not to go if they merely represented the nectar as being this far in that direction, which is all the dance itself tells them. This suggests that they must also have been exploiting something like a cognitive map of their environment, which represents that distance and direction as being in the middle of the lake. ${ }^{22}$

In his (2006, ch. 2), Carruthers interprets the Generality Constraint as a metaphysical constraint on contents rather than a causal constraint on abilities. In doing so, he departs from the interpretation of the Constraint assumed by Evans, McDowell, Peacocke, and others (cf. fn. 3 above). Further, as this passage demonstrates, in his (2004) he interprets the Constraint in terms of abilities: the question of whether bees can think these thoughts is only relevant to the question whether they satisfy the Generality Constraint on an ability-based construal.

In Tautz et al's replication, the bees did follow dances indicating a nectar source on an island, but would not fly to those for a "large and conspicuous boat" (Tautz et al 2004, 919) between the shore and island. Presumably, if the nectar-stocked boat were stationed in one location for long enough, the bees would begin to treat it as an island. It is an interesting question whether any given bee can reconfigure its cognitive map to include a new island, and whether bees would eventually fly to a boat that was always in the lake but in variable locations. If so, this would start to suggest that their representational abilities meet the requirements for basic cognition that I identified above. 
Does this pattern of behavior establish that the bees do understand the thought nectar in lake? It's hard to say. On the one hand, because the representational import of a waggle dance is a compositional function of the dance's shape, orientation, and waggling speed, we have good evidence that the bees are capable of thinking something like nectar there, where there is the location indicated by the dance. We also have evidence, partly from their lack of action in this case but also from the general fact that bees regularly rely on landmarks like lakes to navigate, that they understand something like lake there. It's tempting to conclude that the bees' inaction shows that they have put those two thoughts together to produce the thought nectar in lake, that they 'reject' this thought as absurd, and that they 'infer' from this that nectar there must be false as well.

On the other hand, though, the only thing the bees can do with the thought nectar in lake is ignore it. And this is such a minimal sort of thing to $d o$ with a thought that it's awfully close to not understanding at all; by itself, it's certainly behaviorally indistinguishable from incomprehension. Rather than bringing the two thoughts together to discern a contradiction, the bees might simply be failing to make sense of the thought in the first place. Perhaps their representation nectar there is blocked from interacting with their cognitive map, because the region on the map marked 'lake' can't receive any other markers. In that case, the bees' lack of action would result from a failure of processing, rather than from actively rejecting a comprehended thought as false or otherwise useless.

The general difficulty is that the bees' overall range of needs and actions is so highly restricted that there's not much they can do with any thought. Unless we can identify a wider range of potential actions, or discern finer distinctions among the actions they actually undertake, we lack any possible empirical means for distinguishing active disbelief from either disinterest or blank incomprehension - let alone for distinguishing a distinctively conceptual failure to grasp a potential thought from either a syntactic restriction on recombinability or a merely physical block on neural processing. Thus, in such a minimal context the distinction that Carruthers wants to draw, between being unable to think a thought and lacking a reason to think it, doesn't gain much traction. ${ }^{23}$

23 Bennett (1964) uses roughly analogous reasoning to conclude that bees aren't rational and that their dance does not constitute a language. He goes on to argue that rationality and language are only possible in the context of epistemic reflection and language; I do not find his arguments for the latter conclusion compelling, for the reasons given in $\$ 2$. 
As we consider more complex cognitive systems, the distinction between inability and lack of reason becomes more applicable. Indeed, we might say that the crucial cognitive difference between bees and chimpanzees is that chimpanzees can disengage their representational abilities sufficiently from their current situation to understand how to make some prima facie irrelevant thoughts - thoughts they apparently have no reason to think-relevant. There is one sense in which relevance and absurdity are objective: the bees do objectively have a reason to think the thought nectar in lake, given their interests and the way things are; they just don't realize this. But in another sense, relevance and absurdity are relative: what looks like an absurd thought or an irrelevant detour from one perspective is seen to be relevant and useful from another. In this relative sense, the thought of nectar in the lake is useless to the bee; while to the crow, a straight piece of wire offers the potential of becoming a food-securing hook; and to the chimp, a carved piece of wood affords a means to reel in an out-of-reach platform. The more well-developed a creature's capacity for instrumental reasoning is, the wider a range of represented states of affairs it can see how to make relevant to a given situation; and conversely, the wider a range of situations it will find in which to put a given thought to work. ${ }^{24}$ From a theoretical perspective, this greater grasp on the potential relevance of various thoughts translates into a more general capacity to grasp the potential thoughts produced by combining one's various representational abilities.

Given that chimpanzees are so much better than bees at putting their thoughts to indirect use, we should predict that if they were placed in situations analogous to Gould and Gould's paradigm, they would be able to grasp the situational relevance of some normally

Evans $(1981 / 1985,336-7)$ illustrates this difference in how much a creature can do with its thoughts by appealing to the ways that a rat and a man can each put their beliefs that a certain food is poison:

The rat manifests the 'belief' in only one way — by not eating - whereas there is no limit to the ways in which the ordinary belief that something is poisonous might be manifested. The subject might manifest it by, for example, preventing someone else from eating the food, or by giving it to a hated enemy, or by committing suicide with it... It is of the essence of a belief state that it be at the service of many distinct projects, and that its influence on any project be mediated by other beliefs.... One who possesses a belief will typically be sensitive to a wide variety of ways in which it can be established (what it can be inferred from), and a wide variety of different ways in which it can be used (what can be inferred from it).

In fact, rats can do considerably more with their representations than Evans allows. But his basic point holds: humans can put their representations to work generally, in the service of a wide variety of projects, because they can grasp a wide variety of connections between those representations As a result, many more thoughts of our thoughts have some potential role to play, however indirect, in solving problems. 
absurd thoughts. There is a significant obstacle to directly implementing the Goulds' paradigm with chimpanzees, because chimpanzees lack two of the key mechanisms by which bees can be prompted to represent distant states of affairs: a compositional representational system and cooperative communication. However, enculturated chimps can be trained to use systems of symbols (e.g. Rumbaugh and SavageRumbaugh 1994). Thus, we might minimize these differences by training chimpanzees to compete with each other for rewards by 'reading' combinations of symbols. This training would, of course, induce other significant cognitive changes (Premack 1983). But it would at least allow us to confront the chimpanzees with triggering stimuli for a wide range of thoughts. I predict that given such a set-up, chimpanzees would be able to put some normally useless thoughts to work in recovering rewards from otherwise 'unnatural' locations: to find food in a floating basket, say.

I also predict, though, that many combinations of concepts would remain cognitively empty for them. Once again, the corresponding thoughts needn't be categorially absurd; they might just be naturalistically untenable, like the thought that $_{2}$ is dominant about a highly subordinate chimpanzee, or that $t_{1}$ is offspring about a much older chimp. There are simply no plausible circumstances, even artificially engineered ones, in which such thoughts might be true, or in which instrumental action could make them true. As a result, these thoughts have no possible use for them. We might try to give the chimpanzees a reason to entertain even these thoughts, by offering them rewards for assenting to combinations of symbols corresponding to true thoughts and for dissenting from false ones. Perhaps they could learn to provide appropriate spontaneous responses for thoughts that we have independent reason to think they understand, like banana there. But even so, it seems highly implausible that they could provide such responses for otherwise useless thoughts. For, in the absence of any practical application, the bare difference between truth and falsity itself lacks any relevance. Thus, I doubt that the chimpanzees could get enough of an independent grip on either the thoughts themselves or on their truth-values to appropriately assent to and dissent from the corresponding 'sentences.'

If this prediction were borne out, it wouldn't be appropriate to blame the chimpanzees: we would have asked them to engage in a silly, highly artificial task. However, it is incumbent upon anyone, like Carruthers, who claims that bees or chimpanzees do have the ability to understand such combinations of concepts to offer some paradigm in which these animals can put their putative understanding to work. Unless we can identify some such paradigm, the claim that these animals have the ability to grasp those potential thoughts rests on an 
appeal to behavior in unreal, "phantom contexts" (Evans 1975, 32). In the scenarios I've described, bees and chimpanzees are given both a triggering stimulus and an objective reason to entertain the corresponding thought. If they can't make any active, substantive sense of those thoughts even in these situations, then this should call into question the claim that they satisfy the Generality Constraint even on its weak counterfactual interpretation: there is no possible evidence one can cite to support the claim that their representational abilities are capable of fully general recombination.

\section{§6: Generality, Stimulus Independence, and Criteria for Conceptuality}

So far, I've argued that stimulus-independence is necessary for representational abilities that are systematically recombinable in an actively self-generated way (\$3), and that some significant degree of stimulusindependence is possible in the absence of language and higher-order thought (§4). I've also argued, though, that the degree of stimulusindependence that is practically achievable through non-linguistic instrumental reasoning is unlikely to suffice for fully general recombinability (§5). Although a non-linguistic animal could have a considerably more robust, systematic capacity for instrumental reasoning than chimpanzees actually do, problem-solving alone can't plausibly enable a creature to make substantive sense of - to do something with - all the possible combinations of its representational abilities: some potential thoughts will always remain practically useless to it. Further, there is no obvious alternative capacity besides instrumental reasoning that could plausibly give a non-linguistic creature a reason to think the full range of its potential thoughts.

At this point, then, we can return to our original question: what is required for conceptual thought? From one perspective, so long as we're clear about which cognitive abilities we're discussing, there's no point in fighting about terminology. In light of the previous discussion, we could simply define three distinct concepts of concept: a minimalist "concept $t_{1}$," denoting cognitive, representational abilities that are causally counterfactually recombinable; a moderate "concept ${ }_{2}$," denoting cognitive, representational abilities that are systematically recombinable in an actively self-generated, stimulus-independent way; and an intellectualist "concept 3 ," denoting concept ${ }_{2}$-type representational abilities whose epistemic status the thinker can reflect upon, where we assume that this latter ability is possible only in the context of language.

However, we can also go further, to ask which of these three concepts is most theoretically useful. The minimalist concept $t_{1}$ has the clear advantage of parsimony, because it appeals only to criteria that are 
directly motivated by the basic tasks of concepts: representing and reasoning about particulars and ways of being. Moreover, by virtue of their recombinability and responsiveness to learning, concepts ${ }_{1}$ allow a creature with relatively modest cognitive capacities to respond intelligently when confronted with a fairly wide range of stimuli. At the same time, though, concept ${ }_{1}$ abilities are so cognitively minimal that they encompass a type of engagement with the world that is more like passive triggering than active understanding.

Concept $_{2}$ captures the additional intuition that conceptual thought involves the sort of abstract grasp on a represented state of affairs which enables a thinker to entertain thoughts actively, without any direct prompting. The requirement of stimulus-independence also interacts in important ways with the requirement of recombinability. If the claim that a creature's representational abilities are systematically recombinable is not to be empty, then that creature must be able to actually do something with a wide range of its thoughts. The most minimal sense in which one can do something with a thought is the merely counterfactual one in which, if certain circumstances arose, this would cause one to represent the relevant (possibly spatially and/or temporally distant) state of affairs. Greater stimulus-independence underwrites a comparatively more robust recombinability, with a direct practical benefit: it enables the creature to put a wider range of its thoughts to work in a wider range of circumstances, most notably in the course of instrumental reasoning. The more robust a creature's capacity for instrumental reasoning is, the more thoughts it can do something with, and so the more flexible its cognitive abilities become.

Conversely, robust stimulus-independence also requires recombinability, at least in practice. To make substantive sense of a wide range of thoughts from within a given situation, a creature must be able to put those thoughts to work in a wide range of ways, by grasping a wide variety of direct and indirect connections among those thoughts, and between them and its goals and desires. Although an extensionally equivalent ability could in principle be achieved piecemeal, by employing a plethora of discrete abilities to represent entire states of affairs and to connect them to other representations, it is exponentially more efficient if the creature's underlying representational abilities are themselves systematically recombinable. Representational abilities that already play a functional role at the level of concept $_{1}$, by representing commonly occurring circumstances in a stimulus-dependent manner, can then be recruited as building blocks for increasingly flexible, active thought about increasingly far-flung ends.

Thus, systematic recombinability and stimulus-independence cluster together in a way that makes a practical difference for achieving the 
most basic aim of thought: using information about the world to solve problems and facilitate one's survival and flourishing. I think this is good enough reason to prefer a concept $t_{2}$ notion of concepts over the minimalist concept $t_{1}$ notion.

To motivate the additional conditions imposed by concept $_{3}$, the intellectualist needs to tie those conditions to a basic task of concepts in a way that also makes a practical cognitive difference. And indeed, language does considerably facilitate both stimulus-independence and recombinability. A public language is likely to produce some increase in the range of thoughts that any one thinker has occasion to think, by enabling it to hear others' thoughts. A language, whether public or private, also makes it easier to re-token the same thought in different situations, by supplying a highly abstract, easily replicable medium in which to represent those thoughts (cf. McGeer and Pettit 2002). Further, because language wears its own recombinability on its syntactic sleeve, it makes the potential recombinability of the corresponding thoughts more obvious; and this in turn makes it easier for a thinker to entertain the full range of its potential conceptual combinations. ${ }^{25}$

Finally, if a language is sufficiently expressively powerful, it will include some means for denoting truth-values and for representing inferential connections between thoughts. Once a thinker can symbolically locate a thought within an inferential network of other thoughts, it becomes much easier to trace out its consequences. This has obvious practical advantages, of course, most obviously in the context of sustained instrumental reasoning about complex problems. But it also gives thinkers something to $d o$, however minimal, with even those thoughts that lack any plausible practical application: they can now deduce that, and explain why, those thoughts are necessarily false, probably false, or trivially true, given the further consequences they entail (Camp 2004). It's hard to see how this sort of merely theoretical application for one's thoughts could arise unless one had some explicit means for representing inferential relations; and it's perhaps also hard to see how one could represent such inferential relations in a non-linguistic medium. ${ }^{26}$ If so, and if we make full generality a requirement for conceptual thought, then language and the ability to think higherorder thoughts about inferential relations will indeed be practical requirements for conceptuality.

25 I discuss the expressive implications of the syntactic recombinability of language as compared to other representational systems in my 2009. higher-order thought is possible without language. In my 2007, I argue that cartographic systems can in principle represent negations, disjunctions, and conditionals, but that in a way that is massively more cumbersome than in language. 
However, I don't believe that the theoretical and practical considerations we've identified warrant imposing full generality as an absolute condition on conceptual thought - for any of the three concepts of 'concept' we've identified. Instead, we should view conceptuality as a matter of degree. As Evans himself says, the Constraint is "an ideal, to which our actual system of thoughts only approximately conforms" $(1982,105)$. Given the wide range of concepts we possess, full generality demands that we comprehend absurd thoughts like Julius Caesar is a prime number. Many theorists, including Evans, have wanted to impose categorial restrictions on the Generality Constraint in order to avoid making the comprehension of such thoughts a condition on conceptual competence. I've argued (Camp 2004) that we should reject such categorial restrictions. We cannot demarcate in advance the boundary between substantive thought and empty nonsense, because the line shifts as our imaginative and scientific horizons expand: the thoughts that the mind is the brain and that matter is energy, for instance, once seemed like cross-categorial nonsense but are now core tenets of established scientific theories. Likewise, there is no sharp boundary between those thoughts we ought to be able to think and those whose comprehension is supererogatory. Categorially impeccable thoughts can be as practically useless for us as they are for bees and chimpanzees; while even cross-categorial thoughts may turn out to be relevant, given a wide enough range of goals and long enough chains of inference.

The fundamental intuition behind the Generality Constraint is both sound and important: conceptual thought involves a flexible, abstract grasp on ways for things to be, which one should be able to apply to many different objects. Limitations on the generality of one's ability to apply a concept do represent a kind of cognitive inadequacy - a failure to exercise that ability to its fullest potential. However, such limitations need not exclude one from the realm of conceptual thought entirely. So long as one's cognitive abilities fit the criteria that make talk of concepts explanatorily useful-specifically, so long as one can represent various particulars and ways of being, in various combinations in the absence of those objects and properties themselves - it would be arbitrary and inappropriately over-intellectual to require that one be able to comprehend thoughts that lack any practical relevance. Instead, we should say that the wider the range of potential thoughts one can actively comprehend, and the wider the range of situations in which one can entertain them, the more fully conceptual one's thought becomes.

Language does indeed help us to transcend our current circumstances and represent absent states of affairs. But one can achieve a 
significant degree of both systematicity and stimulus-independence without it. More importantly, language itself doesn't guarantee either full stimulus-independence or full generality. Although we have language, many of our conceptual and linguistic abilities are still fairly stimulus-dependent: we are unable to reliably identify certain colors without the aid of paint chips, for instance, but we can still think about those shades when we do have the chips in hand or have looked at them recently. Likewise, we often fail to entertain thoughts that we have objective reason to think, and so fail to solve problems even when the solution is 'staring us in the face.' We also fall short of full generality: precisely because certain potential thoughts are so absurd, it's unlikely that anyone would ever think them or utter sentences expressing them in any practical context. To probe the farther reaches of our potential conceptual territory, we need more than just language or a capacity for epistemic reflection. We also need the sort of curiosity and imagination that drives practical problem-solving, speculative science and art, and - as Carruthers suggests - philosophy.

Ultimately, then, we need to strike a balance in our understanding of concepts. Conceptual thought is a wondrous thing, but as an increasing number of theorists are arguing, it does not leap full-grown, sheathed in gleaming linguistic armor, into a dull world of brute response to raw stimulus. Rather, it grows naturally out of cognitive abilities that a wide range of animals exhibit to a greater or lesser extent. It also exists alongside non-cognitive abilities that are no less sophisticated or essential to survival and flourishing. While the place of concepts in nature may be special, it is not isolated.

\section{References}

Allen, Colin and Mark Hauser (1996): "Concept attribution in nonhuman animals: theoretical and methodological problems in ascribing complex mental processes," in Readings in Animal Cognition, ed. M. Bekoff and D. Jamieson (Cambridge, MA: MIT Press).

Bekoff, Mark and Dale Jamieson (1996): Readings in Animal Cognition (Cambridge MA: MIT Press).

Bennett, Jonathan (1964): Rationality: An Essay Towards an Analysis (London: Routledge and Kegan Paul).

Bermudez, José Luis (2003): Thinking without Words (Oxford: Oxford University Press).

Bisch-Knaden, Sonja and Rüdiger Wehner (2001): "Egocentric information helps desert ants to navigate around familiar obstacles," Journal of Experimental Biology 204, 4177-4184. 
Boesch, Christopher and Hedwige Boesch (1990): "Tool use and tool making in wild chimpanzees," Folia Primatologica 54, 86-99.

(1984): "Mental maps in wild chimpanzees: an analysis of hammer transports for nut cracking," Primates 25,160-170.

Bugnyar, Thomas and Bernd Heinrich (2006): "Pilfering ravens, Corvus corax, adjust their behaviour to social context and identity of competitors," Animal Cognition 9:4, 369-376.

— (2005): "Ravens, Corvus corax, differentiate between knowledgeable and ignorant competitors," Proceedings of the Royal Society B 272, 1641-1646.

Byrne, Alex (2004): "Perception and conceptual content," in Contemporary Debates in Epistemology, ed. E. Sosa and M. Steup (Oxford: Blackwell).

Byrne, Richard and Andrew Whiten (1990): "Tactical deception in primates: the 1990 database," Primate Report 27, 1-101.

Call, Josep (2001): “Chimpanzee social cognition," Trends in Cognitive Sciences 5:9, 388-393.

Camp, Elisabeth (2009): "A language of baboon thought?" in Philosophy of Animal Minds, ed. R. Lurz (Cambridge: Cambridge University Press).

- (2007): "Thinking with maps," Philosophical Perspectives 21: Mind ed. J. Hawthorne (Oxford: Blackwell).

- (2004): "The Generality Constraint and categorial restrictions," The Philosophical Quarterly 54: 215, 209-231.

Carey, Susan (1985): Conceptual Change in Childhood (Cambridge, MA: MIT Press).

Carruthers, Peter (2006): The Architecture of the Mind: Massive Modularity and the Flexibility of Thought (Oxford: Oxford University Press).

— (2004): “On being simple minded," American Philosophical Quarterly 41, 205-22; reprinted in Consciousness: Essays from a HigherOrder Perspective (Oxford: Oxford University Press, 2005).

Chomsky, Noam (1966/2002): Cartesian Linguistics: A Chapter in the History of Rationalist Thought, 2nd ed. (Christchurch, New Zealand: Cybereditions).

Crane, Tim (1992): "The nonconceptual content of experience," in The Contents of Experience, ed. T. Crane (Cambridge: Cambridge University Press), 136-157.

Cussins, Adrian (1992): "Content, embodiment and objectivity: the theory of cognitive trails," Mind 101, 651-688.

Davidson, Donald (1999): “The emergence of thought," Erkenntnis 51, 7-17.

(1982): “Rational animals," Dialectica 36, 317-328. 
(1975/1984): "Thought and talk," in Mind and Language, ed. S. Guttenplan (Oxford: Oxford University Press), 7-23; reprinted in Inquiries into Truth \& Interpretation (Oxford: Oxford University Press 1984), 155-170.

Davies, Martin (1991): "Concepts, Connectionism, and the Language of Thought," in Philosophy and Connectionist Theory, ed. W. Ramsey, S. Stich and D. Rumelhart (eds.) (Hillsdale, NJ: Lawrence Erlbaum and Associates), 229-257.

Descartes, René (1637/1985): "Discourse on the method of rightly conducting the reason and seeking for truth in the sciences," in The Philosophical Writings of Descartes vol. 1, ed. J. Cottingham, R. Stoothoff and D. Murdoch (Cambridge: Cambridge University Press).

De Waal, Frans (1996): Good Natured: The Origins of Right and Wrong in Humans and Other Animals (Cambridge, MA: Harvard University Press).

Dretske, Fred (1999): "Machines, plants and animals: the origins of agency," Erkenntnis 51, 19-31.

(1994): "If you can't make one, you don't know how it works," in Midwest Studies in Philosophy 19, ed. P. French, T. Uehling and H. Wettstein (Notre Dame: University of Notre Dame Press), 468-482. (1990): "Putting information to work," in Information, Language, and Cognition, ed. P. Hanson (Oxford: Oxford University Press), $112-140$.

Dummett, Michael (1994): The Origins of Analytic Philosophy (Cambridge, MA: Harvard University Press).

Evans, Gareth (1981/1985): "Semantic theory and tacit knowledge," in Wittgenstein: To follow a rule, ed. S. Holtzman and C. Leich (London: Routledge and Kegan Paul), 118-137; reprinted in his Collected Papers (Oxford: Clarendon Press), 322-342.

- (1982): The Varieties of Reference (Oxford: Oxford University Press).

(1975): "Identity and predication," Journal of Philosophy 72:13, 343-363.

Fodor, Jerry (1990): A Theory of Content and Other Essays (Cambridge MA: MIT Press).

(1987): Psychosemantics (Cambridge, MA: MIT Press).

Fodor, Jerry and Zenon Pylyshyn (1988): "Connectionism and cognitive architecture: a critical analysis," Cognition 28, 3-71.

Gallistel, C. Randy (1998): "Brains as symbol processors: the case of insect navigation," in An Invitation to Cognitive Science, vol. 4: Conceptual and Methodological Foundations 2nd ed., ed. S. Sternberg and D. Scarborough (Cambridge, MA: MIT Press), 1-51. 

Press).

(1989): "Animal cognition: the representation of space, time and number," Annual Review of Psychology 40, 155-189.

Gibson, Kathleen and Tim Ingold, eds. (1993): Tools, Language and Cognition in Human Evolution (Cambridge: Cambridge University Press).

Gould, James and Carol Grant Gould (1988): The Honey Bee (New York: Science American Library).

Hauser, Mark (2000): Wild Minds: What Animals Really Think (New York: Holt).

Hauser, Mark, Noam Chomsky and Tecumseh Fitch (2002): "The faculty of language: what is it, who has it, and how did it evolve?" Science 298, 1569-1579.

Heck, Richard (2000): "Nonconceptual content and the "space of reasons'," Philosophical Review 109:4, 483-524.

Hernnstein, Richard, Donald Loveland and Cynthia Cable (1976): "Natural concepts in pigeons," Journal of Experimental Psychology, Animal Behavior Processes 2, 285-302.

Hunt, Gavin R. and Russell D. Gray (2004): "The crafting of hook tools by wild New Caledonian crows," Proceedings of the Royal Society of London B 271, S88-S90.

Köhler, Wolfgang (1925): The Mentality of Apes (New York: Harcourt and Brace).

Lethmate, Jürgen (1982): "Tool-using skills of orangutans," Journal of Human Evolution 11, 49-64.

McDowell, John (1994): Mind and World (Cambridge, MA: Harvard University Press).

McGeer, Victoria and Philip Pettit (2002): "The self-regulating mind," Language and Communication 22:3, 281-299.

Melis, Alicia, Brian Hare and Michael Tomasello (2006): "Chimpanzees recruit the best collaborators," Science 311: 5765, 1297-1300.

Millikan, Ruth Garrett (1998): "A common structure for concepts of individuals, stuffs, and real kinds: More Momma, more milk, and more mouse," Behavioral and Brain Sciences 21, 55-65.

- (1986): "Thoughts without laws: cognitive science with content," Philosophical Review 95, 47-80.

- (1984): Language, Thought and Other Biological Categories (Cambridge MA: MIT Press).

Mithen, Steven (1996): The Prehistory of the Mind: A Search for the Origin of Art, Science and Religion (London: Thames \& Hudson/Orion).

Morris, Richard (1981): "Spatial localization does not require the presence of local cues," Learning and Motivation 12, 239-260. 
Müller, Martin and Rudiger Wehner (1988): "Path integration in desert ants, Cataglyphis fortis," Proceedings of the National Academy of Science U.S.A. 85, 5287-5290.

Origgi, Gloria and Dan Sperber (2000): "Evolution, communication and the proper function of language," in Evolution and The Human Mind, ed. P. Carruthers and A. Chamberlain (Cambridge: Cambridge University Press).

Peacocke, Christopher (2001): "Does perception have a nonconceptual content?" Journal of Philosophy 98:5, 239-264. (1992): A Study of Concepts (Cambridge, MA: MIT Press).

Perner, Josef (1991): Understanding the Representational Mind (Cambridge, MA: MIT Press).

Premack, David (1983): "The codes of man and beast," The Behavioral and Brain Sciences 6, 125-167.

Price, Huw (1990): "Why 'Not'?" Mind, 99:394, 221-238.

Rumbaugh, Duane and E. Sue Savage-Rumbaugh (1994): "Language in comparative perspective," in Animal Learning and Cognition (Handbook of Perception and Cognition, 2nd ed.), ed. N. J. Mackintosh (San Diego, CA: Academic Press), 307-333.

Sanz, Crickette, David Morgan and Steve Gulick (2004): "New insights into chimpanzees, tools, and termites from the Congo Basin," American Naturalist 164, 562-581.

Schmidt, I., Thomas Collett, Dillier, F.-X. and Rüdiger Wehner. (1992): "How desert ants cope with enforced detours on their way home," Journal of Comparative Physiology A 171, 285-288.

Speaks, Jeff (2005): "Is there a problem about nonconceptual content?" Philosophical Review 114:3, 359-398.

Spelke, Elizabeth (1985): "Perception of unity, persistence, and identity: thoughts on infants' conceptions of objects," in Neonate cognition: Beyond the Blooming Buzzing Confusion, ed. J. Mehler and R. Fox (Hillsdale, NJ: Lawrence Erlbaum Associates).

Stammbach, Eduard (1988): "Group responses to specially skilled individuals in a Macaca fascicularis group," Behaviour 107, 241-266.

Strawson, Peter (1963): Individuals: An Essay in Descriptive Metaphysics (Garden City NJ: Anchor Books).

Suddendorf, Thomas and Andrew Whiten (2001): "Mental evolution and development: evidence for secondary representation in children, great apes, and other animals," Psychological Bulletin 127:5, $629-650$.

Tautz, Juergen, Shaowu Zhang, Johannes Spaethe, Axel Brockmann, Aung Si and Mandyam Srinivasan (2004): "Honeybee odometry: performance in varying natural terrain," Public Library of Science: Biology 2:7, 915-923. 
Tolman, Edward C. (1948): "Cognitive maps in rats and men," Psychological Review 55, 189-209.

Tomasello, Michael (2000): The Cultural Origins of Human Cognition (Cambridge, MA: Harvard University Press).

Tomasello, Michael, Josep Call and Brian Hare (2003): "Chimpanzees understand psychological states: the question is which ones and to what extent," Trends in Cognitive Sciences 7, 153-156.

Visalberghi, Elisabetta, Dorothy Fragaszy and Sue Savage-Rumbaugh (1995): "Performance in a tool-using task by common chimpanzees (Pan troglodytes), bonobos (Pan paniscus), an orangutan (Pongo pygmaeus), and capuchin monkeys (Cebus apella)," Journal of Comparative Psychology 109:1, 52-60.

Weir, Alex, Jackie Chappell and Alex Kacelnik (2002): "Shaping of hooks in New Caledonian crows," Science 297, 981.

Whiten, Andrew and Richard Byrne (1988): "Tactical deception in primates," Behavioral and Brain Sciences 11, 233-273.

Wimmer, Heniz and Joseph Perner (1983): "Beliefs about beliefs: representation and constraining function of wrong beliefs in young children's understanding of deception," Cognition 13, 103-128. 